\title{
ANÁLISE COMPARATIVA DA EFICIÊNCIA ENERGÉTICA ENTRE SISTEMAS PREDIAIS DE ABASTECIMENTO DE ÁGUA
}

\author{
Enio Carlos Segatto ${ }^{1}$ \\ André Marcelo Dias ${ }^{2}$
}

\begin{abstract}
Resumo: Segundo a norma técnica brasileira ABNT-NBR5626/1998, as edificações brasileiras devem possuir reserva de água suficiente para garantir o abastecimento para um dia de consumo normal. Este fato remete à existência de reservatórios inferiores e/ou superiores, pressupondo a aplicação dos sistemas indiretos de abastecimento de água potável. Assim, três configurações básicas para os sistemas indiretos de abastecimento de água são aplicáveis no Brasil: o sistema RI/RS que é dotado de dois reservatórios e um sistema de bombeamento para elevar o líquido do reservatório inferior para o superior; o sistema RI que possui apenas o reservatório inferior e um sistema de bombeamento que é responsável pelo abastecimento direto dos pontos de consumo da edificação a partir de uma prumada principal e o sistema RI com a prumada segmentada em zonas de pressão, identificada neste artigo simplesmente por RI-Z. O presente trabalho teve como objetivo analisar qual dos três sistemas aplicáveis é mais eficiente do ponto de vista energético. Para isso, estabeleceram-se perfis para análise comum de edificações com 8, 12 ou 16 pavimentos e, através do Simulink, criou-se modelos computacionais que possibilitaram a simulação do abastecimento com a análise da energia necessária para movimentação das bombas nas aplicações tanto em velocidade fixa que é aplicável no sistema RI ou variável, presente nos sistemas RI e RI-Z. Desta forma, os resultados encontrados após as simulações demonstram, de forma concisa, que as edificações dotadas de sistemas de pressurização do tipo RI-Z apresentam-se como sendo mais eficientes, obtendo potencial de economia e preservação energética de até $40 \%$ em relação aos outros sistemas, dependendo do perfil da edificação.
\end{abstract}

Palavras Chaves: Sistemas de abastecimento de água, eficiência energética, bomba, motobomba.

\begin{abstract}
According Brazilian Standard ABNT-NBR5626/1998, the Brazilian buildings must have water reservation enough to guarantee the supply during one day of normal consumption. This fact brings the existence of upper and lower water tanks with application of indirect system to supply drinking water. Then, three basic configurations of indirect water supply systems are applicable in Brazil: the RI/RS system which is dotted of two reservoir with one pumping system to transport the liquid from lower to upper reservoir; the RI system that has only lower reservoir and one pumping system to supply the main pipe where is connected every hydraulic devices of building and RI system with main pipe segmented in pressure zones that in this article is identified by RI-Z. This job was objective to analyze which applicable system has the best energetic efficiency. To analyze that, a common profile of buildings with 8, 12 and 16 floors was established and, through Simulink, computational models were created to simulate of water supply with analysis of needed energy to move the pumps with fixed speed, applicable on RI/RS system and variable speed, used on RI and RI-Z system. The end result presents that the buildings dotted with RI-Z system are the most efficient with potential of energy savings up to $40 \%$, according building profile.
\end{abstract}

Key words: Water supply systems, Energetic efficiency, pump, motor pump.

\footnotetext{
1 Departamento de Eletrotécnica - Instituto Federal de Ciência e Tecnologia de São Paulo. E-mail: segatto@ifsp.edu.br

${ }^{2}$ Programa de pós graduação em Automação Industrial e Controle de processos - Instituto Federal de Ciência e Tecnologia de São Paulo. E-mail: amarcdias@gmail.com
} 


\section{Introdução}

A água potável é um essencial nutriente para o qual não existe substituto. $\mathrm{E}$, para que os consumidores possam fazer o bom uso dela, esta precisa chegar aos pontos de consumo em quantidade suficiente e dentro de valores prédeterminados de pressão.

Isso implica que os edifícios, de uma maneira geral, devem, obrigatoriamente, possuir sistemas hidráulicos prediais que garantam, nos pontos hidraulicamente mais críticos, a pressão suficiente para proporcionar conforto e segurança aos consumidores finais.

Tais fatos, aliados á tendência da verticalização das construções residenciais e comerciais nas grandes cidades, fazem com que os sistemas de pressurização sejam cada vez mais aplicados com a finalidade de garantir ao consumidor o fornecimento de água potável com pressões em níveis constantes e satisfatórios.

Esses sistemas podem ser concebidos de maneiras diferentes, entretanto, todas elas passam pela necessidade da aplicação das motobombas. É justamente neste ponto, segundo Almeida (2007), onde se encontram os maiores problemas: estimase que $2 / 3$ das moto-bombas instaladas estão consumindo até $60 \%$ mais energia do que o necessário.

De acordo com Chaguri Junior (2009), discussões em torno de usos finais de energia são válidas e devem ser ampliadas, porém, elas devem ser feitas incorporando análises sobre os projetos de construção da infraestrutura que vão determinar as características do uso final da energia na edificação ao longo se sua vida útil.

Os erros de dimensionamento ocorrem especialmente pelo desconhecimento dos critérios eficientes para seleção dos equipamentos e sistemas ou até mesmo por direcionar as designações exclusivamente com vistas aos custos iniciais. Considera-se, muitas vezes, que o custo energético da operação correrá à custa dos futuros usuários do sistema.
Haestad (2003) afirma que os problemas operacionais mais comuns que contribuem para o desperdício de energia são:

1. As bombas operam em pontos hidráulicos diferentes daqueles que se esperava que operassem quando no projeto;

2. As bombas foram originalmente selecionadas com base em certo tempo de ciclo, mas acabam por operar de forma contínua; e

3. Bombas com velocidade variável operando em pontos de baixa eficiência energética.

Por detrás desses erros dimensionais ou operacionais está o fato de que muitos empreendedores não se preocupam com a eficiência energética da instalação em si, basta a esses, no entanto, somente que o abastecimento ocorra.

\section{Objetivo}

O objetivo principal deste trabalho é contribuir para a racionalização energética auxiliando no custo do abastecimento de água nas edificações através da comparação do consumo energético dos sistemas de abastecimento de água aplicáveis nos edifícios brasileiros. Para isso, leva-se em consideração a energia mecânica necessária na movimentação das bombas aplicadas em cada um desses sistemas.

\section{Desenvolvimento}

Para se alcançar os resultados esperados deste trabalho, as seguintes etapas preliminares foram desenvolvidas:

Análise das características
principais dos sistemas de
abastecimento de água predial;
2Adoção de edifício modelo e
definição de premissas para o
dimensionamento e simulação dos
modelos observando os critérios
estabelecidos na norma brasileira
NBR5626/1998: Instalações prediais
de água fria;
Definição do modelo computacional
e simulação operacional desses 
modelos no Simulink, com a medição do consumo energético de cada um.

\subsection{Sistemas de abastecimento de água predial}

De acordo com Azevedo Netto (1998), define-se por sistema de abastecimento de água o conjunto de obras, equipamentos e serviços destinados ao abastecimento de água potável a uma comunidade para fins domésticos, de serviços públicos, consumo industrial ou para outros usos. A água fornecida pelo sistema deverá ser em quantidade suficiente e com qualidade, do ponto de vista físico, químico e bacteriológico.

Os sistemas de abastecimentos de água prediais podem ser configurados como diretos ou indiretos. Nos sistemas diretos, não existe reservatórios de água entre a rede pública e os pontos de consumo da edificação. Considerando que a NBR5626/1998 estabelece a necessidade da reserva mínima de água para o abastecimento pleno de toda e qualquer edificação durante 24 horas, os sistemas diretos não são aplicáveis no Brasil.

Conforme observado por Ilha (2004), o sistema de abastecimento indireto é aquele que possui ao menos um ponto de reserva de água e, a partir do qual, se alimenta a rede de distribuição.

De acordo com a localização dos reservatórios na edificação, os pontos de consumo podem ser pressurizados pela própria gravidade (reservatório sobre $\mathrm{o}$ edifício) ou por sistema de bombeamento (a partir de reservatórios inferiores).

Considerando ainda que a conexão de sistemas de bombeamento diretamente à rede pública é proibida pelas autarquias responsáveis pelo abastecimento de água, no Brasil, o sistema de abastecimento indireto pode ser instalado de três maneiras diferentes:

1.Sistema com reservatórios inferior e superior, com um sistema de bombeamento para recalque de água entre eles, neste artigo é identificado por "sistema RI-RS";

2. Sistema indireto dotado apenas do reservatório inferior, a partir do qual a prumada edificação é abastecida contando com a operação de um único sistema de bombeamento. Neste artigo, é identificado por "sistema Rl";

3. Sistema indireto dotado apenas do reservatório inferior, com a prumada segmentada, dividindo o abastecimento predial em zonas de pressão. Nesse caso, para cada uma das zonas de pressão, haverá um sistema de bombeamento independente. Neste artigo, esse sistema está identificado por "sistema RI-Z".

\subsubsection{Sistema RI-RS}

Este sistema é composto por um alimentador predial com válvula boia, reservatório inferior, sistema de bombeamento e rede de distribuição.

Para o bom funcionamento deve existir uma chave boia elétrica no reservatório superior. Quando certo nível (médio do reservatório) é atingido, o comando para ligar o sistema de bombeamento é disparado.

Quando o reservatório superior tem sua capacidade máxima atingida, então um comando para desligamento do sistema de bombeamento é emitido.

O reservatório inferior é dotado de uma válvula tipo boia para permitir o abastecimento pela rede pública e, usualmente, também possui uma boia elétrica que impede o funcionamento do sistema de bombeamento quando o reservatório estiver vazio.

A figura 1 ilustra o sistema RI/RS de uma edificação

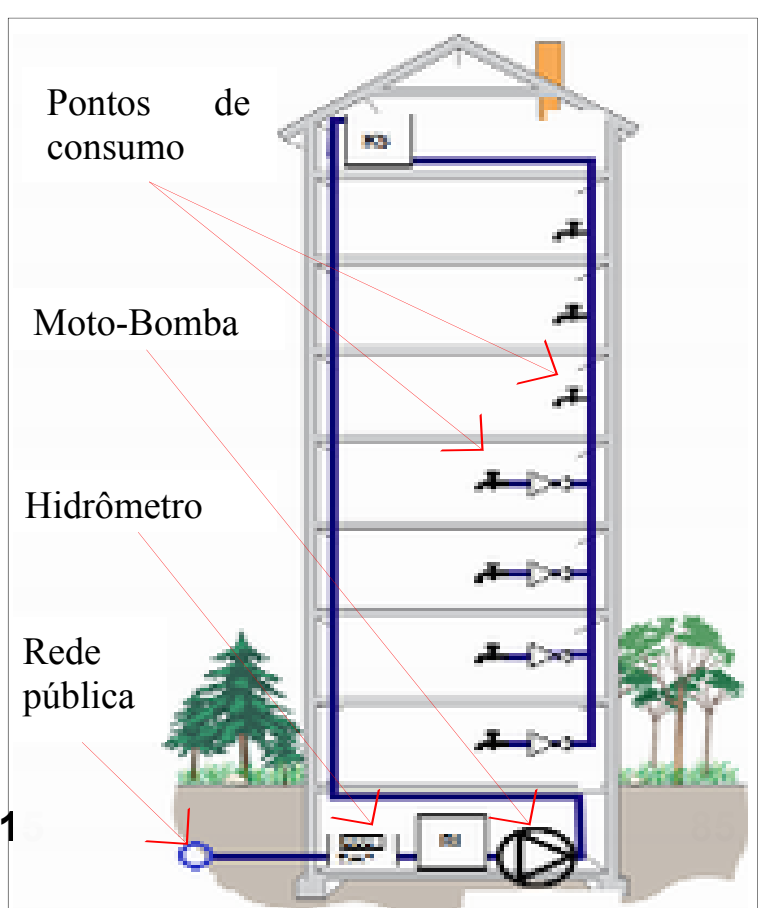


Observa-se, portanto, que os sistemas indiretos $\mathrm{RI} / \mathrm{RS}$ apresentam as seguintes vantagens:

Rede predial menos expostas às falhas da rede pública, uma vez que possuem reservatórios que garantem por algum tempo o abastecimento;

P.ossibilidade de programar o horário para operação dos sistemas de bombeamento;

Em contrapartida possuem as seguintes desvantagens:

1.Possibilidade de contaminação da água nos reservatórios;

2Maior custo na estruturação do prédio, uma vez que necessitará suportar os esforços do reservatório instalado na cobertura;

Menor área útil na cobertura devido ao volume ocupado pelos reservatórios;

4ecessidade da instalação de válvulas redutoras de pressão (VRP's) nos pavimentos mais baixos devido às pressões excessivas nesses pontos.

\subsubsection{Sistema RI}

O sistema de abastecimento indireto RI não possui reservatório superior sendo composto por um sistema de bombeamento com recursos para controle de pressão (usualmente baseado no controle de velocidade do motor), reservatório inferior e pela rede de distribuição.

Para garantia do conforto do usuário, a pressão de abastecimento hidráulico deve manter-se constante, independente dos níveis de consumo da edificação.

Por isso os sistemas de bombeamento destinados para abastecimento dos sistemas RI geralmente operam em malha fechada com um transmissor de pressão realimentando o sistema de controle, que, por sua vez, atua na variação da velocidade das motobombas, buscando manter o valor de pressão ajustado no setpoint.

O sistema de bombeamento deve ser especificado para atendimento à vazão máxima de projeto, considerando o pico de demanda e de forma que a pressão de saída possa garantir o abastecimento confortável ao pavimento mais elevado da edificação, mas, ao mesmo tempo não deve ultrapassar os limites máximos de pressão nos pavimentos inferiores.

A figura 2 ilustra o sistema RI de uma edificação.

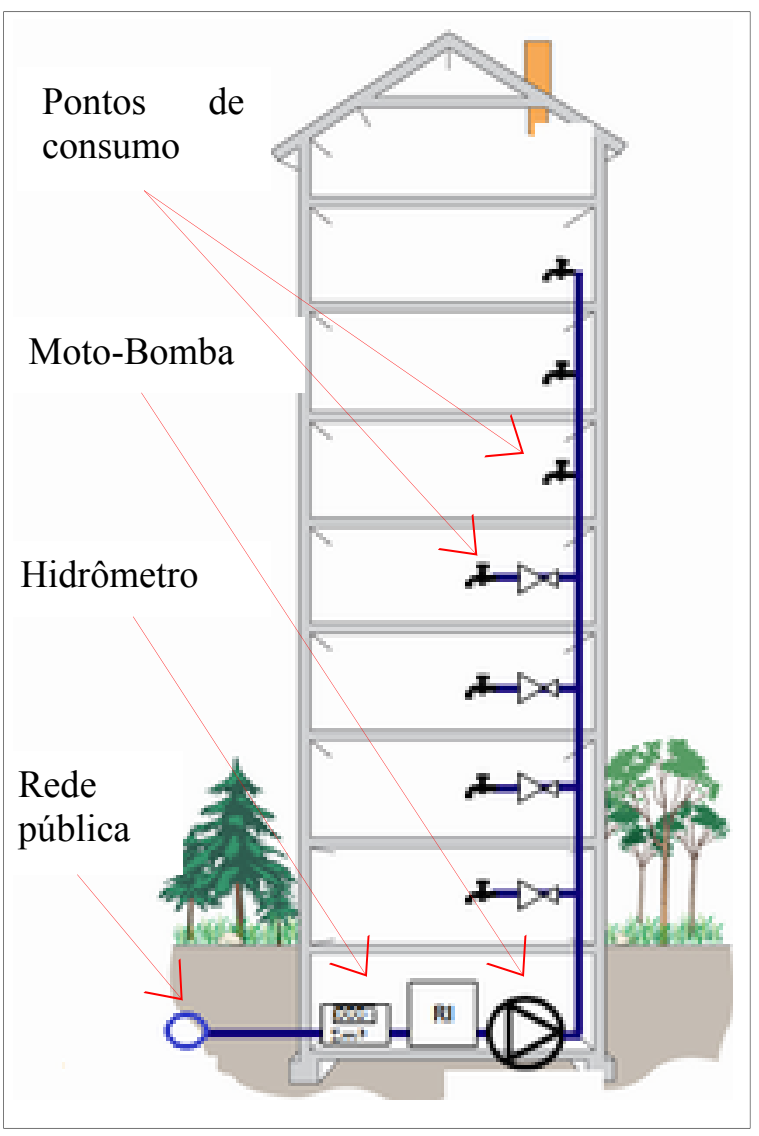

Figura 2 - Sistema RI

Fonte: autor

$\mathrm{O}$ sistema indireto RI sem reservatório superior apresenta as seguintes vantagens:

1. Diminuição dos custos estruturais devido à diminuição das cargas pela não existência de reservatório superior;

2. Permite a utilização do espaço que seria utilizado pelo reservatório superior;

Por outro lado, o sistema RI apresenta, também, algumas desvantagens: 
1. Faz-se necessária a aplicação de geradores de energia para manutenção do sistema de bombeamento em funcionamento quando na falta de energia elétrica.

2.Por possuir um sistema de controle eletrônico, necessita de pessoal qualificado para realização de manutenções no conjunto, sempre difícil de encontrar-se no ramo da construção civil.

3.Necessitam ainda das VRP's por também possuírem pressões excessivas nos pavimentos inferiores

\subsubsection{Sistema RI-Z}

$\mathrm{O}$ sistema de abastecimento indireto RI-Z é composto pelos mesmos componentes e possui as mesmas características funcionais do sistema RI, entretanto, possui a prumada de abastecimento da edificação dividida para o abastecimento da edificação segmentado em zonas de pressões.

Desta maneira, é necessária a instalação de tantos sistemas de bombeamento quantas forem as zonas de pressão da edificação.

A figura 3 a seguir ilustra um sistema de abastecimento predial RI-Z com duas zonas de pressão.

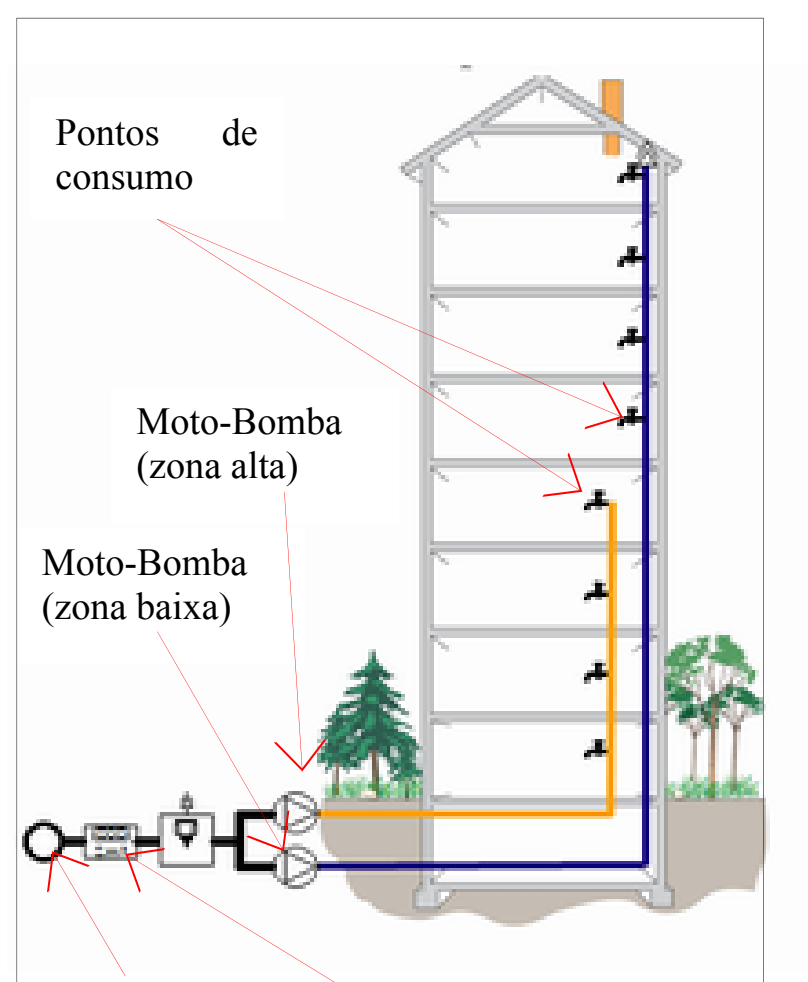

Rede

pública

Hidrômetro
Assim, além das vantagens já mencionadas no sistema RI, o sistema RI-Z possibilita a eliminação parcial ou total das válvulas de redução de pressão nos pavimentos inferiores por proporcionar o abastecimento desses pavimentos com pressões mais baixas e, portanto, adequadas para o conforto do usuário.

Exceção à instalação das VRP's, as desvantagens apresentadas pelo sistema RI$\mathrm{Z}$ são as mesmas que as do sistema RI.

\section{Rremissas adotadas simulações}

O tamanho e a disposição interna das unidades residenciais são variáveis no mundo todo, de tal maneira que se pode encontrar desde aquelas destinadas para moradia de uma única pessoa até os apartamentos de luxo com centenas de metros quadrados de área privativa.

A área útil das unidades prediais bem como a quantidade de habitantes previstas para cada uma delas são fatores que influenciam diretamente no dimensionamento do abastecimento de água, assim, pode-se dizer que a análise do abastecimento de água em todas as variações prediais seria trabalho para alguns anos.

Portanto, para comparar o consumo energético entre os diferentes sistemas de abastecimento predial, um modelo único de apartamento foi definido como padrão de análise. Este apartamento padrão é composto por 3 dormitórios, 3 sanitários, sala, cozinha e área de serviço tendo sua área útil privativa estimada em cerca de $100 \mathrm{~m}^{2}$.

Considerou-se que a altura do pé direito de cada pavimento é de 3 metros e que o sistema de bombeamento, sempre estará instalado no pavimento térreo, junto ao reservatório inferior.

$\mathrm{O}$ reservatório superior, onde aplicado, sempre estará localizado sobre o último pavimento, com sua conexão hidráulica de entrada em uma cota de 3 metros em relação ao piso onde está 
instalado.

Adotou-se também que a análise será realizada sob um universo de edificações com 8,12 ou 16 pavimentos contendo 4,8 ou 12 apartamentos padrão em cada um deles.

Da mesma maneira, estimou-se que 5 pessoas habitem cada um destes apartamentos, fazendo uso dos dispositivos hidráulicos instalados nos sanitários, cozinha e área de serviço, dispostos em quantidade tipicamente encontrada em apartamentos com este perfil, conforme demonstrado na tabela 1:

Tabela 1 - Pontos de consumo previstos para o modelo adotado

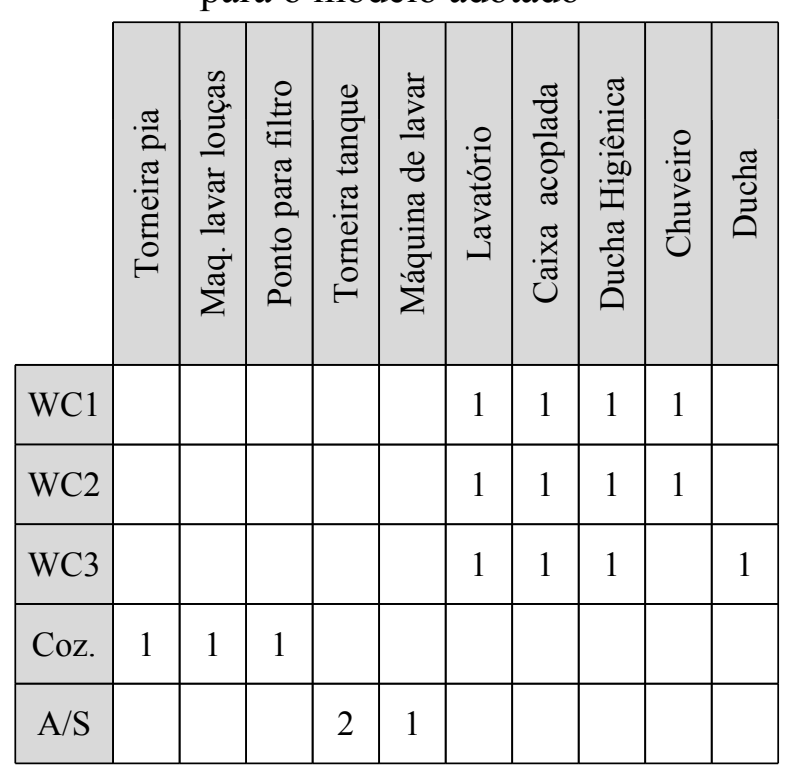

Onde:

$\mathrm{WC}=$ banheiro;

Coz. $=$ cozinha, $\mathrm{e}$

$\mathrm{A} / \mathrm{S}=$ área de serviços

A partir da adoção desse modelo, se fez necessário o dimensionamento dos componentes do sistema de abastecimento de água bem como da forma de operação para simulação dos sistemas. Assim, os tópicos que seguem demonstram os valores determinados ou adotados para as simulações realizadas.

\subsubsection{Reserva mínima e consumo diário}

Conforme sugerido por Ilha (1994), determinou-se o consumo diário da edificação e, consequentemente o tamanho da reserva de água necessária, através da equação 1:

$$
C_{\mathrm{d}}=C \cdot P[l]
$$

Onde:

$\mathrm{Cd}=$ Consumo diário da edificação [l]

$\mathrm{C}=$ Consumo diário per capita [l]

$\mathrm{P}=$ População do edifício [número de pessoas]

\subsubsection{Perfil de consumo}

Barreto (2008) demonstra, através do seu estudo, um perfil de consumo médio residencial na cidade de São Paulo, tomando como base medições realizadas em diferentes pontos da cidade.

Os resultados apurados estão representados de forma percentual na figura 4 e foram adotados como base para a análise do edificações.

\subsubsection{Pressão na sucção da bomba}

A pressão hidráulica presente no flange de sução da bomba nos sistemas 
prediais é variável e seu valor resultante está em função da pressão atmosférica exercida sobre a superfície da lâmina d'água no reservatório, da altura dessa mesma lâmina e das perdas de carga no trecho de tubulação entre o reservatório inferior e o flange de sucção da bomba.

No intuito desses fatores variáveis não interferirem nas simulações de desempenho da máquina, convencionou-se que, a pressão hidráulica no flange de sucção da bomba será sempre nula.

\subsubsection{Pressões nos pontos de consumo}

Considerando os valores mínimos previstos na NBR5626/1998 e os valores empiricamente aplicados pelos projetistas de sistemas hidráulicos prediais, para se determinar a altura manométrica necessária na moto-bomba, adotou-se que no caso do sistema RI-RS, a pressão mínima na válvula boia instalada na conexão de entrada do reservatório superior deve ser, no mínimo, 3 m.c.a.

Para o abastecimento através do sistema RI, adotou-se que a pressão mínima na conexão da prumada do último pavimento seja, no mínimo, 10 m.c.a..

\section{2.Đeterminação das perdas de carga e cálculo da altura manométrica da bomba}

Através das vazões de cada instalação juntamente com os diâmetros das tubulações definidos, as perdas de carga poderiam ser determinadas para cada uma das instalações. Para isso, bastaria definir um trajeto padrão para a tubulação nas edificações e então calcular as perdas localizadas e o comprimento total equivalente da tubulação através das fórmulas de Fair-Wipple-Hsiao ou Hazen_Williams.

Contudo, ainda que os trajetos sejam similares, a diferença na velocidade do fluído dentro da tubulação traria valores de perdas de carga diferentes para cada edificação que, por sua vez, influenciaria diretamente na análise do consumo energético.

Assim, para suprir as perdas de carga na tubulação, considera-se padronizar $10 \%$ sobre o valor total da altura manométrica projetada em todos os casos analisados neste trabalho.

Desta forma, a equação 2 foi aplicada para determinação da altura manométrica diferencial para a motobomba.

$$
H=\left(H_{\text {geo }}+H_{\text {cons }}\right) \cdot 1,1[m, c, a]
$$

Onde:

$\mathrm{H}=$ Altura manométrica total a ser fornecida pela bomba [m.c.a.];

$\mathrm{H}_{\text {geo }}=$ Desnível geométrico entre o eixo do flange de recalque da bomba e o ponto mais alto de abastecimento [m];

$\mathrm{H}_{\text {cons }}=$ Pressão nos pontos de consumo dos sistemas RI ou na válvula boia do sistema RI-RS [m.c.a];

$1,1=$ Coeficiente adotado para suprir as perdas de carga na tubulação.

\subsubsection{Divisão em zonas de pressão}

$O$ critério estabelecido para divisão em zonas de pressão no sistema RI-Z foi a eliminação de todas as válvulas redutoras de pressão instalados nos pavimentos com a manutenção da pressão de abastecimento entre os valores máximo, estabelecidos pela NBR5626/1998, e mínimo, conforme assumido no tópico 3.2.4.

Assim, considerando que a altura do pé direito de cada pavimento é sempre 3 metros, empiricamente, adotou-se que cada zona de pressão será composta por 4 pavimentos. A divisão feita desta maneira faz com que o desnível geométrico entre o pavimento mais alto e o mais baixo de cada zona de pressão seja sempre 12 metros.

Como a pressão mínima na conexão da prumada do pavimento mais alto de cada zona de pressão deve ser 10 m.c.a, logo, a pressão nos dispositivos instalados no pavimento mais baixo será de 22 m.c.a., desconsiderando-se as influências das perdas de carga.

\subsubsection{Determinação da vazão da moto-bomba no sistema RI/ RS}

A vazão nominal para escolha da bomba a ser aplicada nas simulações dos modelos dotados de sistema RI/RS foi 
determinada dividindo-se o consumo total diário pelo número de horas de operação diária da bomba.

A NBR5626/1998 prevê que o abastecimento de grandes reservatórios deva ser feito em até 6 horas diárias, valor adotado para simulação do abastecimento no sistema RI-RS.

\subsection{LBeterminação da vazão máxima instantânea}

Para dimensionamento da tubulação da prumada de abastecimento principal da edificação e para determinar a vazão para abastecimento do sistema RI, é necessário conhecer vazão instantânea máxima provável da edificação.

Assim, a NBR5626/1998 estabelece a mínima vazão por dispositivo sanitário bem como o método dos pesos para a determinação das vazões na tubulação.

No método dos pesos, a quantidade de cada dispositivo é multiplicada pelos correspondentes pesos relativos. A partir da somatória dos pesos relativos, pode-se encontrar, portanto, a vazão instantânea máxima provável da tubulação, conforme demonstrado na equação 3 , a seguir:

$$
Q p=0,3 \sqrt{\sum P}
$$

Onde:

Qp = Vazão máxima instantânea provável [1]

$\mathrm{P}=$ Peso relativo dos dispositivos sanitários conforme tabela A1 da NBR5626/1998.

Através da equação 3, observa-se que as moto-bombas que operam nos sistemas RI e RI-Z sempre estão dimensionadas com capacidade de abastecimento para os momentos mais críticos.

\subsubsection{Seleção da moto-bomba}

Buscando a situação mais próxima da realidade, a escolha das moto-bombas para operação nas edificações analisadas foi realizada a partir da linha de produtos comercialmente disponível para aquisição no mercado nacional.

Os dados operacionais desses equipamentos foram coletados a partir das declarações do fabricante ao órgão federal regulador desse mercado.

\subsubsection{Dimensionamento dos tubos}

A NBR5626/1998 estabelece que a velocidade máxima do fluído nas instalações não deva ultrapassar os $3 \mathrm{~m} / \mathrm{s}$, para que não se estabeleça um sistema turbulento, comprometendo-se assim, o desempenho do sistema.

Assim, para dimensionamento dos tubos das edificações simuladas, adotou-se a equação da simultaneidade, representada na equação 4:

$$
D=\sqrt{\frac{4 \cdot Q}{\pi \cdot V_{\max }}}[\mathrm{m}]
$$

Onde:

$\mathrm{D}=$ Diâmetro mínimo da tubulação [m]

$\mathrm{Q}=$ Vazão na tubulação $\left[\mathrm{m}^{3} / \mathrm{s}\right]$

$\mathrm{V}_{\max }=$ Velocidade máxima do fluído na tubulação [m/s]

\subsection{Modelo computacional para simulação do sistema RI/RS}

Para simulação no Simulink, estabeleceu-se um modelo computacional que representa com fidelidade a operação do sistema RI/RS, sendo representado de forma simplificada na figura 5 .

Pode-se notar através do esquema acima que o sistema RI-RS é sempre um sistema que opera em malha aberta, não havendo controle de velocidade para a moto-bomba.

Os sensores aplicados no modelo tiveram funcionalidade apenas indicativa, não influenciando, portanto, na operação do sistema.

Como este trabalho tem por objetivo a análise do consumo energético, o ramal de abastecimento das unidades consumidoras, instalado a partir do reservatório superior e pressurizado pela gravidade foi desconsiderado. 


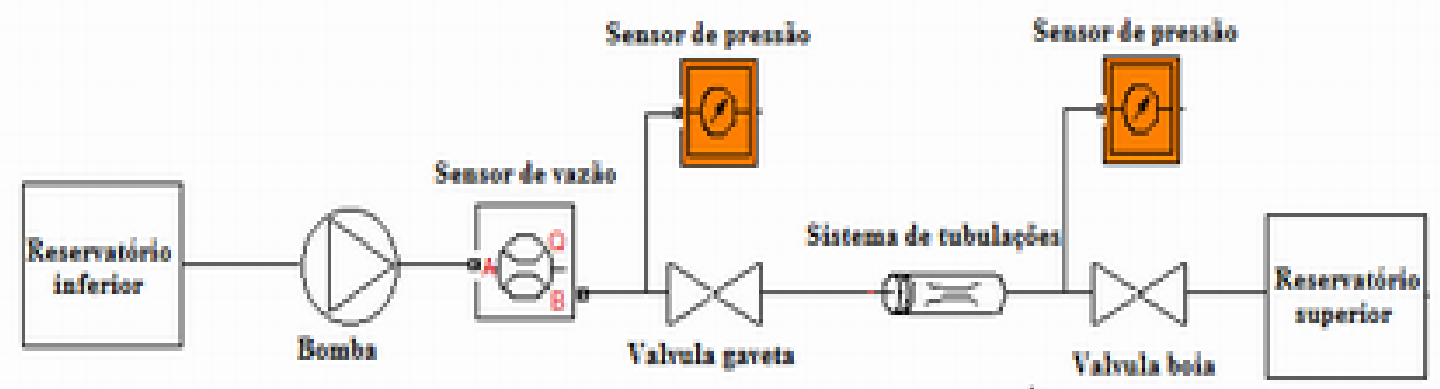

Figura 5 - Representação simplificada do sistema RI-RS. Fonte:

Autor

\subsection{Esquema em blocos do modelo computacional adotado para simulação dos sistemas RI e RI-Z}

Analogamente ao item anterior, a figura 6 representa o modelo simplificado utilizado no Simulink para simulação dos sistemas RI e RI-Z.

Observa-se que para pressurização ascendente (sistemas RI e RI-Z), se faz necessária a variação da velocidade da moto-bomba através de um controle em malha fechada realimentado pelo sensor de pressão instalado imediatamente após o sistema de bombeamento.
Desta forma, quando há a variação no consumo de água acusa a variação na pressão de abastecimento provocando a imediata atuação do controle sobre a velocidade da bomba, buscando corrigir a perturbação c ausada.

Portanto, a velocidade das motobombas é variável de acordo com o consumo, buscando-se manter a pressão do sistema em níveis constantes, de acordo com o setpoint projetado.

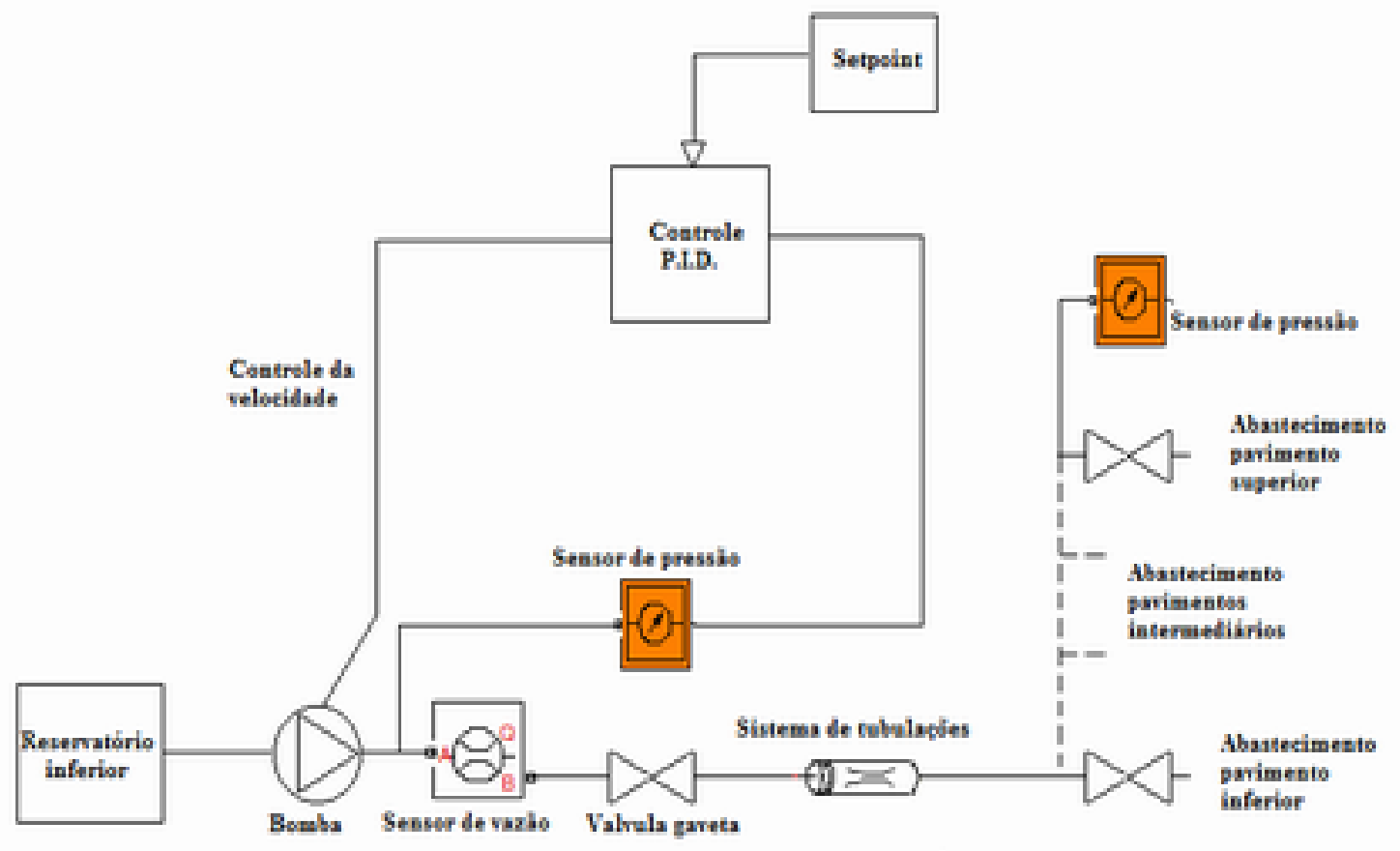

Figura 6 - Representação simplificada dos sistemas RI e RI-Z

Fonte: autor 


\section{Análise Conclusiva}

Com os resultados obtidos nas simulações no Simulink foi possível conhecer as características de operação e do consumo energético dos principais sistemas de abastecimento prediais existentes no Brasil.

Desta maneira, a tabela 2, demonstra as relações entre o consumo energético (em KW) e o volume de água bombeado $\left(\mathrm{em} \mathrm{m}^{3}\right)$ para os diferentes sistemas, considerando-se as médias de consumo energético agrupados em edificações com o mesmo número de pavimentos.

Os mesmos resultados são apresentados de forma gráfica, na figura 7 .

Tabela 2 - Consumo KW/m $/ \mathrm{m}^{3}$ nas simulações realizadas

\begin{tabular}{|c|c|c|c|}
\hline $\begin{array}{l}\text { Sistema } \\
\text { Edifício }\end{array}$ & RI-RS & RI & RI-Z \\
\hline $\begin{array}{c}8 \\
\text { pavimentos }\end{array}$ & 0,183 & 0,188 & 0,162 \\
\hline $\begin{array}{c}12 \\
\text { pavimentos }\end{array}$ & 0,275 & 0,275 & 0,194 \\
\hline $\begin{array}{c}16 \\
\text { pavimentos }\end{array}$ & 0,306 & 0,311 & 0,227 \\
\hline
\end{tabular}

simulações realizadas.

Nos pavimentos mais baixos dos sistemas RI-RS e RI, a energia adicionalmente consumida para elevar a água a alturas maiores é, depois, dissipada nos dispositivos para redução da pressão instalados em cada pavimento para se obter a pressão de abastecimento dentro de valores seguros e confortáveis ao usuário final.

Desta maneira, pode-se entender que outro ponto vantajoso para o sistema RI-Z é a possibilidade da otimização do consumo energético em edificações com população rotativa, como hotéis, por exemplo; a possibilidade de ocupação gradativa da edificação a partir dos pavimentos mais baixos proporciona o acionamento prioritário das unidades de bombeamento com menor consumo energético.

Por outro lado, um fato não menos importante demonstrado nas análises realizadas é o sobre dimensionamento que o método dos pesos proporciona às bombas destinadas à operação nos sistemas RI e RI-Z. Como necessitam atender os picos da demanda no abastecimento, essas bombas possuem capacidade disponível muito maior que a vazão efetivamente bombeada na maior

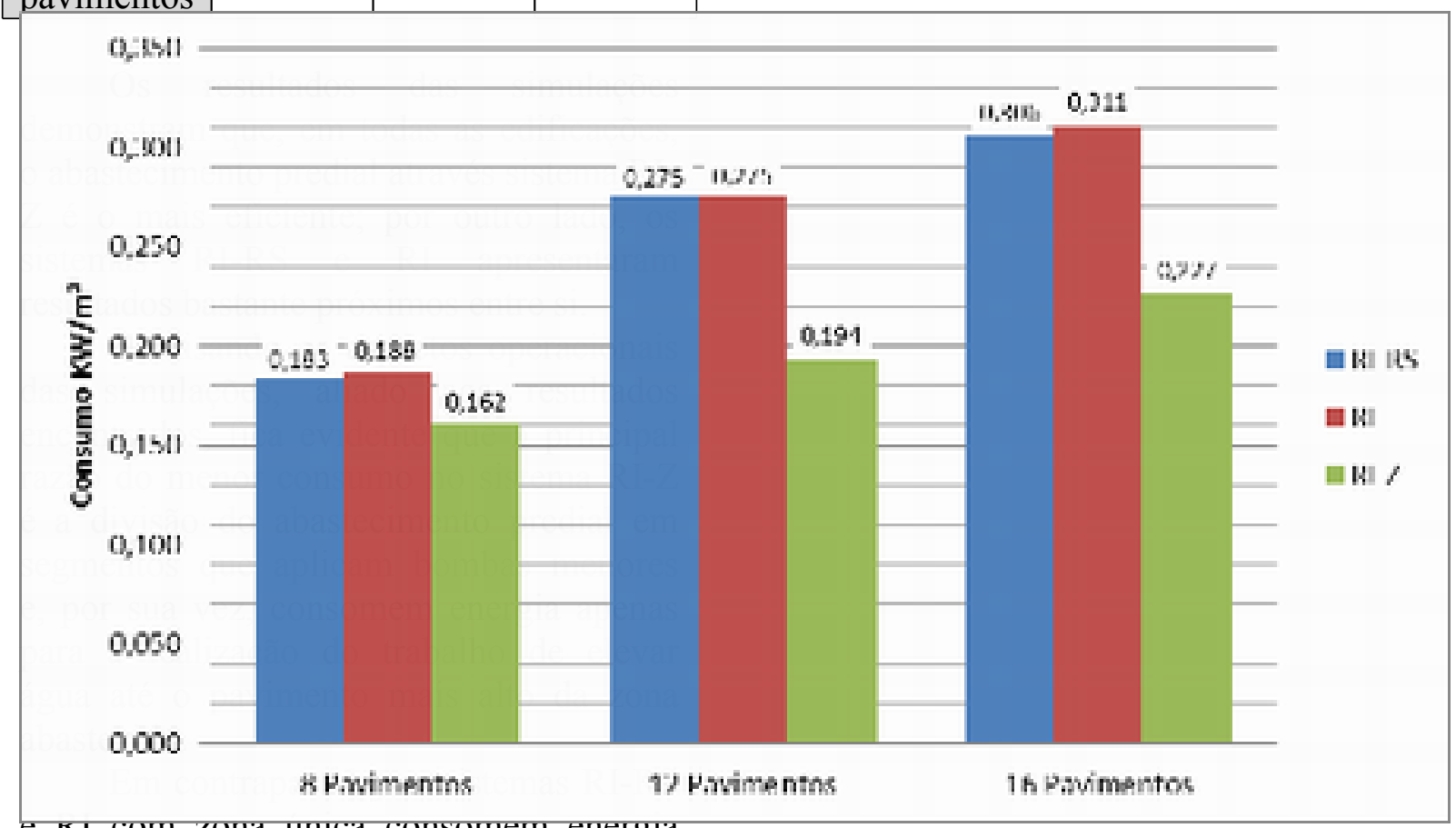

para elevar água até o ưftimo pavimento $\mathrm{da} / \mathrm{m}^{3}$ nas simulações realizadas

edificação. Essa característica comufronte: autor

justifica os resultados bastante próximos

parte do tempo.

obtidos pelos dois sistemas durante as 
Esse fato leva a bomba à operação em pontos de menor rendimento. Assim, com vistas à melhoria na eficiência dos sistemas RI e RI-Z, os projetistas de sistemas prediais devem sempre agrupar o maior número possível de pontos de consumo que necessitam da mesma altura manométrica, e, portanto, que possam ser abastecidos pela mesma bomba.

Por exemplo, os projetos para os sistemas de abastecimento de conjuntos prediais, podem utilizar a mesma unidade de bombeamento para abastecer zonas de pressão correlatas de edificações diferentes.

Outra possibilidade de solução é a divisão da vazão máxima instantânea em duas ou mais bombas operando em cascata. Desta maneira, a capacidade total de bombeamento continua a respeitar o estabelecido pela norma NBR5626/1998, no entanto, as bombas, sendo menores, operam utilizando uma parcela maior da sua capacidade.

Recomenda-se para estudos futuros, a ampliação deste trabalho, incluindo o modelamento do consumo dos motores elétricos em conjunto com seus dispositivos de comando e/ou controle.

Da mesma maneira, sugere-se desenvolver sistemas de controle que promovam a operação das moto-bombas nas faixas de melhor rendimento, observando o comportamento sazonal do consumo de água nas edificações.

\section{Referências Bibliográficas}

A.W.CHESTERTON, 2000. Pump Principles Manual. Stoneham: A.W.Chesterton.

ALÉ, J. A. V., 2010. Sistemas Fluidomecânicos. Porto Alegre: PUC-RS.

ALMEIDA, A. T., 2007. Relatório Motors Final, Coimbra: Universidade de Coimbra.

Associação Brasileira de Normas Técnicas, 1998. NBR5626 : Instalação predial de água fria. Rio de Janeiro/RJ: ABNT.
BARRETO, D., 2008. Perfil do consumo residencial e usos finais da água. São Paulo: IPT - Instituto de Pesquisas Tecnológicas de São Paulo.

BURT, C., 2006. Electric Motor Efficiency under variable frequency and loads. s.1.:California Polytechnic state University.

EUROPUMP; Hydraulic Institute, 2001. Pump life cycle costs: A guide to LCC analysis for pumping system. New Jersey: Belgium.

EUROPUMP; Hydraulic Institute, 2004. Variable speed pumping. A guide to successful applications. Bodmin, Cornwall: Elsevier.

GIRDHAR, P., 2005. Practical Centrifugal Pumps: Design operation and maintenance. Burlington: Elsevier.

GURGEL, B., 2006. Proposição de uma metodologia para avaliação de inversores de frequencia em estações elevatórias de água. São Paulo/SP: EPUSP.

HAESTAD, M., 2003. Advanced Water Distribution Modeling and Management. Waterbury: Haestad Methods Inc..

ILHA, M. S. D. O., 1994. Sistemas Prediais de água fria. São Paulo/SP: EPUSP.

KARASSIK, I. J., 1986. The Pump Handbook. New York: McGraw-Hill.

LAHR, P. T., 1999. Cavitation and NPSH in Centrifugal Pumps. Centrifugal Pumps Handbook, pp. 6-7.

MESQUITA, A. L. A., 2007. Utilização de bombas centrífugas em velocidade variável para a redução do consumo de energia. s.1.:Universidade Federal do Pará.

NETTO, A., 1998. Manual de Hidráulica. São Paulo: Blucher.

BACHUS, L., 2003. Know and Understanding Centrifugal Pumps. New York: Elsevier. 
WEG S.A., 2009. Motores de Indução Alimentados por Inversores de Frequencia $P W M$. Jaraguá do Sul / SC: Weg S.A..

WILO AG, 2005. Fundamental Principles of pump technology. Dortmund: Wilo AG.
WILO AG, 2008. Pressure Boosting Technology. Dortmund: Wilo AG. 